\title{
Medicine at a Distance in Sweden: Spatiotemporal Matters in Accomplishing Working Telemedicine
}

\author{
Jesper Petersson
}

This paper examines the accomplishment of making technology work, using the discourse around telemedicine in Swedish healthcare during 1994-2003. The paper will compare four projects launched in the mid-1990s and policymakers' visions of healthcare through telemedicine. I will employ a sociotechnical approach developed within Actor-Network Theory that understands functioning technology not as something intrinsic but as an outcome of an ongoing process of negotiations. In the paper, I will extend the sociotechnical approach of what constitutes working technology to include spatiotemporal matters. I will also approach the closely related issue of space that has become a concern of Actor-Network Theory scholars interested in the accomplishment and continued workings of technology as it travels. In this discussion, an emphasis on fixed relations (network space) has been challenged by investigations into changing relations (fluid space). This paper suggests that in order to travel well, technology must be both fixed and fluid. ${ }^{\circ}$

Keywords: telemedicine, spatiotemporality, post-Actor-Network Theory, ICT

\section{Introduction}

Telemedicine is a so-called diffuse technology, meaning that it is not limited to a specific area of application. Hence, it is difficult to comment on telemedicine generally. Among the interviewees, the concept has varied somewhat in content depending on differences in experience and perspectives. Hence, it is important to remember that telemedicine is heterogeneous. Many different applications already exist, and presumably more will be discovered. (Landstingsförbundet, Federation of Swedish County Councils, 2000a, b: 6.)

Healthcare systems in many countries currently turn to information and commu- nication technology (ICT) to address pressing challenges. This paper will investigate the workings of one of these modes of practicing medicine by ICT, which has been given the name telemedicine. The topic to be addressed is the working of telemedicine within Swedish healthcare.

Many social scientists within the field of Science and Technology Studies (STS) have stressed that to explain the success of technology and understand how it is made to work, one must study technology as a heterogeneous set of relations that shifts between contexts. From the above quote it may seem that the Federation of Swedish County Councils (henceforth FCC) shares the view of STS analysts. But rather 
than helping the FCC to understand telemedicine, this heterogeneity presumably makes it difficult to capture its content. Being hard to depict as a black box - that is, fixed, stable and certain - it is described, instead, as being diffuse; in motion, its use vague and its future unclear ${ }^{1}$. This paper will investigate how the varying state of telemedicine contributed to its attractiveness, on the one hand, and led bodies such as the FCC to question its existence, on the other.

During the 1990's telemedicine gained considerable attention within Sweden, as well as internationally, as a way of addressing citizens' demands of increasing healthcare services while simultaneously trying to contain costs. By making use of a technology that already, in its name, promised to link together things and people 'at a distance' (tele), various actors within the healthcare system came to investigate the application of telemedicine to reallocate care. But as May and associates (2001) have pointed out in an analysis of telemedicine in a British context, while it has been possible to make telemedicine applications work to investigate, diagnose and treat patients at the clinical level, it has been very difficult to demonstrate that such applications can actually contribute to a more rational use of healthcare resources. Similarly, many of the actors that will be encountered in this paper give accounts of situations where the result of putting in place electronically mediated medicine to decrease the burden upon specialist resources in fact resulted in the opposite.

To understand some of the complexities of translating clinical practices of telemedicine into visions of a more streamlined healthcare provision, I will use the sociotechnical approach developed within STS, which understands technology as always implicated in the continuous negotiation of the social (Latour, 1987). This approach runs counter to, for instance, the linear diffusion approach (Rogers, 1995) because in the linear diffusion approach technology is conceptualized as static and artefactual, i.e. having demarcated boundaries. Technological innovations are treated as closed, finished products that are 'released' into society where they travel through it, staying the same everywhere, always, becoming either accepted or rejected. The sociotechnical approach argues instead that the considered success or failure of technology is always dependent upon the context of application. Hence, the functionality of technology cannot be determined from the outset but is always understood as situated. Arguing for the situatedness of technology requires avoiding a pre-determined boundary between the material and the social, and instead investigating their intertwinement into a sociotechnical web. However, as the sociotechnical approach has argued that the material cannot be split from the social in studying the workings of technology, this paper will, by a focus upon distance, extend the analysis of working technology so as to include spatiotemporal matters. In this paper, therefore, I will study actors' involvement in various efforts at formatting distance to accomplish functioning telemedicine; that is, how they came to define problems relating to distance differently, hence taking different views concerning what actions were necessary to overcome them. In a word, I will not treat distance as an absolute entity 'out there', but as something which is patterned and intertwined with actor's achievements of attempting to make telemedicine work. To do so, I will contrast four examples of the practicing of telemedicine in Sweden to address the availability of care and where issues of distance came to the fore in different ways, leading to multiple configurations of telemedicine. For reasons of clarity, the four projects will 
be named 'the Eye'; 'the Heart'; 'the North' and 'the South', pointing to their difference in medical conditions addressed and where they took place.

In following these different formattings of distance in the performance of telemedicine, I will demonstrate telemedicine's somewhat conflicting position within Swedish healthcare, contrasting differences between telemedicine as a national technology and as a localized technology; between the urge for coordination and control, and the quest for adaptability in the pursuit of making telemedicine work. In doing so, this study contributes to discussions within the sociotechnical framework of fixed and fluid spaces (Law, 2002; Law \& Mol, 2001; Murdoch, 1998), the former represented by coordinated technology, the latter by adaptable technology. I will show how telemedicine dissolved before the eyes of healthcare management bodies and policy agencies. Their envisioned version of telemedicine as a way of streamlining the delivery of care within the Swedish healthcare system became challenged by versions of situated practices of telemedicine that instead would demand increased resources.

The paper is organized as follows. First I will describe the sociotechnical approach and introduce the body of work on space and time within the ANT framework, relating it to the field of ICT. The section entitled 'Topological Spaces' elaborates upon more recent efforts by ANT scholars to understand the functionality of technology as context-dependent and varying. Then I discuss the authors of the texts to be analyzed. The four projects are presented, highlighting their shifting conceptions of distance and how they became intertwined with matters around accomplishing working technology. I then relate these telemedicine projects and their different distances to distances pursued in the national healthcare agenda. After that follows a concluding discussion.

\section{Heterogeneous Networks and Spatiotemporal Formations}

How technology comes to work has been a major topic in STS (Bijker, 1995; de Laet \& Mol, 2000; Latour, 1987). As mentioned in the introduction, a common denominator in these accounts has been not to understand 'working' as an inherent property of technology but as an emerging quality and, further, not to treat the social and the technical as separate entities, but as embedded in each other. "[T]he technical is, always, already, contained in the social. And...the social is always already, located in the technical" (Law \& Mol, 1995, quoted from Hinchliffe, 1996: 664). Therefore ANT scholars argue for the necessity of investigating the intertwinement of the social and the technical into heterogeneous networks comprising both humans and nonhumans in understanding why technology works, or fails. Hence, working technology should be understood as emerging out of actors' successful accomplishment in building sociotechnical networks consisting of heterogeneous entities (see Latour 1987).

In taking the full consequence of the necessity of integrating non-humans in analyses of the workings of technology, the theoretical framework developed within ANT does not attribute agency only to any form in the social realm but to whatever is allowed to act (Callon, 1991: 140). Therefore agency is not treated as something residing in, for example, humans but is understood as distributed through the heterogeneous networks of human and non-human actors. But as will become apparent in the two examples of 'the North' and 'the South', non-human actors in this 'material semiotics' are not only understood as coming in the shape of the 'technical 
stuff' such as the hard and software of ICT and medical instruments. Whereas these will be centred in 'the Eye' and 'the Heart' projects, the role of the material in the paper's discussion of 'the North' and 'the South' projects will instead focus upon how where one lives, including what is commonly referred to as 'the forces of nature', can come to matter for what telemedicine becomes.

To encompass the many workings of telemedicine, it is however not enough to address the sociomaterial; one should also take into account spatiotemporal matters. The body of work within ANT that address the spatiotemporal is, to a large extent, in line with much contemporary human geography as it does not believe that "space and time [are] existing independently as an unshakable frame of reference inside which events and place would occur" (Latour, 1987: 228, Italics in original). Instead space and time should be thought of as varying, multiple, productive, and produced, emerging out of changing processes and relations. Because, as Murdoch (1998) points out, scholarly work within ANT has repeatedly shown how space/ time is not only folded but caught up in actors' work to mobilize humans and nonhumans into networks whereby diverse places and times are gathered "within common frames of reference and calculations" (1998: 360), leading to the emergence of new combinations of space/time And, as he continues, this accordingly also makes distance something that comes to change shape as it is drawn into different sets of relations. Or as Quattrone and Hopper (2005: 740) summarize, drawing upon Thrift (1996): "distance is not an objective measure of preordained features but is defined by actors, and the instruments of control and knowledge used to manage it."

The possibility of folding space and time to address issues of distance is why tele- medicine has been called upon in healthcare. Telemedicine applications are put in use to cross various boundaries, making it possible to make use of that which is elsewhere, such as specialist resources. They are part of the emergence of a range of ICT-based innovations for reordering the healthcare landscape, for instance by reconfiguring notions of centre and periphery (Cartwright, 2000: 348). But as Oudshoorn (2010) has pointed out, this should not be understood as merely in line with a more rational way of delivering healthcare; one also has to be sensitive to how these technologically mediated shifts affect the nature of medicine, changing notions of proximity. This is in line with the argument made by Graham (1998), that the possibility of folding space and time by ICT should not be interpreted as the production of a separate virtual spatiotemporality, eliminating space/time as we know it, making distance disappear. Instead Graham, building upon ANT, proposes an understanding of technology as becoming entangled in already existing, complex, constellations of humans, non-humans and space/time. Hence, in the analysis of the four projects it will be shown how actors' engagement in battling various distances by ICT did not make these distances disappear without a trace. Instead the reconfigurations they accomplished brought with them predicted as well as unpredicted changes of medical practice and the reorganization of clinical work with political consequences relating to the issue of availability of care.

As has been shown above, the matter of distance is nothing new to ANT. Already in the first 'textbook' of ANT (Latour, 1987), the conceptual construct 'action at a distance' played a central role. It was developed to explain the establishment of centres that could exert domination and control by imposing their version of knowledge 
and order onto other places. Through making use of inscriptions (for instance charts, images, tables, etc.) it became possible to draw together different parts of the world into an aggregated format, making it combinable, stable and simultaneously easily movable (so called immutable mobiles). By such inventions the centre could create a knowledge leverage that fantastically facilitated the possibility of controlling events 'at a distance'. However, this conceptual construct works badly in this paper. Firstly, while issues of order and control will surface amongst various policy actors in the paper, the analysis of the four projects will show that actors turned to telemedicine for purposes completely at odds with the one Latour wanted to capture with 'action at distance'. Instead of being about strengthening the role of medical centres of expertise, creating power hierarchies, the application of ICT to address issues of distance was supposed to even out differences and inequalities between specialists and non-specialists. Hence, instead of order and control the projects focused on distribution and cooperation. Secondly, the emphasis in early ANT studies of actors striving to accumulate knowledge in order to build centres of dominance has had consequences for the conceptualization of what constitutes working technology. By proceeding from the view of the centre, explanations of how working technology was accomplished were predicated on the assumption that central actors set in place fixed, black boxed and hegemonic technology allowing them to take control 'at a distance' over remote settings (Latour, 1987; Law, 1987). These studies have been criticized as being too Machiavellian, disregarding alternative patterns (for such more elaborate accounts see for instance Star, 1991; Haraway, 1997). In this paper it will be demonstrated that technology can travel from one context to another without being coordinated from a centre of expertise, the implication being that the decision as to whether telemedicine works is not in the hands of any single node in the network, but is a far more complex and distributed affair.

\section{Topological Spaces}

More recent studies within the ANT framework, however, have been much more sensitive to difference and multiplicity (de Laet \& Mol, 2000; Law, 2002; McLean \& Hassard, 2004). In their study of the Zimbabwe bush pump, for instance, de Laet and Mol (2000) argue that "fluid" technology works because of its very ability to shift relations and adapt. The pump's inventor is said to have deliberately let go of it. So, according to de Laet and Mol there is no centre coordinating times and spaces. Instead the pump changes depending on circumstances. Parts are dropped and others are added as the purpose of the pump's existence come to vary according to different needs. Going through the pump's varying identities the authors describe it as simultaneously "a mechanical object...a hydraulic system, but...also a device installed by the community, a health promoter and a nation-building apparatus. It has each of these identities - and each comes with its own different boundaries" (de Laet \& Mol, 2000: 225). As opposed to the space of fixed relations in networks we are now in fluid space where the working(s) of the pump is/are an effect of changing relations. On the topic of distance, Mort et al. (2003) have described a somewhat similar situation in the U.K. telemedicine, pointing to how there is not just one version of distance but many, which yet come together and strengthen telemedicine as a clinical field. But telemedicine is not bound to clinical work. As May et al. have argued 
in the context of telemedicine and for healthcare technology in general:

\begin{abstract}
In late modernity, the institutional superstructure of healthcare rests largely on the application of technologies to problems of understanding the nature and distribution of disease, its diagnosis, treatment and management, and the organisation of service provision. These technologies may take the form of machines, or systems, or of practices. Some are hardware, others are software; some are embodied in people, others in objects. Many take the form of hybrids and networks in which the boundaries between the 'social' and the 'technical' are hard to locate, and when they can be, seem often to be ambiguous or permeable. (May et al., 2003: 697, Italics in original.)
\end{abstract}

Hence, healthcare technologies come to be different things in the continuing negotiations between actors, changing identity between places, medical practices, visions, systems, management ideals, policy circles etc. But as Oudshoorn (2010) has pointed out, the clinical reality does not always align with the beliefs of policy actors. Where the former often practise a medical version of telemedicine, the latter largely consider telemedicine as a way to address organizational matters by technology (Mort et al., 2004). In such instances of confusion over appropriate use, actors can engage in the work of coordination and coherence by, for instance, imposing constraints, downplaying some versions and highlighting others, seeking to take control and fix the technology in a preferred shape. Here then fluid relations encounter an urge for frozen ones. In trying to understand the existence of fluid and fixed relations, ANT scholars have borrowed the concept of topology from mathematics: an investigation of the continuity of shape as an object is bent and stretched, understanding fluidity and fixity to be two differ- ent topological configurations (Law, 2002: 94 ), and calling for a geography that queries the pleating of formalized and fluid spaces (Murdoch 1998: 370). This argument will be built upon in the end of the paper to analyze the events around the turn of the century amongst Swedish policymakers with ambitions of extending the use of telemedicine.

\section{The Organizational Landscape of Telemedicine in Sweden}

The Swedish healthcare system is primarily financed by local taxes administrated by the regional county councils. The parliament and government decide on legal regulations, overall direction and structure, but leave it very much to the local county councils how to implement the directives. Until recently the Federation of County Councils represented the councils in negotiations between the councils and the government and its authorities on topics considered in need of national coordination. Both the government and the FCC, the latter through its IT Council, brought forward telemedicine as a technology with transformative potential upon Swedish healthcare in the mid 1990s, at a time when it was moving towards so called "patient centered care" ${ }^{2}$ (prop. 1995/96:125, (1996): 75-77; The Federation of County Councils, 1997: 9). To the IT Council, telemedicine was part of the need for a "boundless" IT $^{3}$ support that would accompany the patient without any operational, administrative or geographical obstacles, demanding national coordination (Federation of County Councils, 1997). In similar terms, the government framed telemedicine as a means to offer high quality, but increasingly scarce, specialist resources to all parts of the country (prop. 1995/96:125, (1996): 77). Both the FCC and the government have, since the mid 1990's, issued various publications 
discussing telemedicine, culminating with the government initiated Vård ITiden report published in 2002 (Ds, 2002:3, for reasons of simplicity it will hereafter be entitled IT in Health Services of Tomorrow, the name used in an English summary of the report).

To coordinate efforts, the government and the FCC turned to the Swedish Institute for Health Service Development (Spri). Spri's overall objective was to work towards a more efficient healthcare sector while simultaneously improving the quality of care, trying to facilitate communication within the healthcare sector (Spri, 1999a). To Spri, telemedicine was nothing new, and it already had a telemedicine working group. Almost all of its members were health economists, not medical professionals.

When Spri was closed down in 1999, Carelink took over the coordinating function in telemedicine. Carelink (closed down in 2007) was created with the sole purpose of focusing and coordinating the developing area of IT and ICT within Swedish healthcare. Many of the health economists at Spri's telemedicine group continued their work at Carelink. Carelink's function has been described by healthcare researchers as similar to that of Spri, on one hand measuring, evaluating and mediating information at the clinical level and, on the other, communicating governance ideals and management practices with the goal of making medical practice governable at an aggregated level (Bejerot \& Hasselbladh, 2008: 111). Thus, to Spri and Carelink, telemedicine became part of their efforts to increase the alignment of medicine with the governing of healthcare by ICT.

The work by Spri to link clinical practice to national healthcare ambitions became particularly evident in the South and the Heart projects' efforts to redistribute specialist resources. Spri became engaged in them because it saw these projects as "...important to the healthcare system at large" (Spri, 1997: 15), with the stated aim of serving as a test bed for forthcoming telemedicine projects put forward by central agencies. These two telemedicine projects, financed by the county councils, were part of a range of ongoing activities in the densely populated southern parts of Sweden to "develop a healthcare without geographical boarders, with an unbroken healthcare chain at all levels". Its overarching purpose was to increase efficiency by ICT by "accommodating the need for information and knowledge to facilitate the decision-making process and planning around every individual patient" (Spri, 1997: 1). The aim of the South project was to wire radiologists together at local, county and university hospitals, in order to make use of resources more efficiently in diagnostic imaging, in a broad range of areas such as computer tomography, magnetic resonance and ultrasonography. The Heart project, on the other hand, focused only on patients with cardiac insufficiency, linking cardiology specialists with GPs through video conferencing every second week.

Both the South project, part of a larger effort to merge the three most southern counties into what would become the Scania region, and the Heart project in the neighbouring south east county of Blekinge, were under the supervision of the Collaboration Board of the South Healthcare Region. It coordinated activities of joint interest for all counties in the southern part of Sweden. None of the medical doctors participating in these projects seems to have taken an interest in publishing anything about them. Instead the published accounts from the South project have been made by spokespersons at different levels of management, cooperating with Spri. In the Heart project the only published material seems to be an exten- 
sive evaluation report that the board called upon Spri to perform, interviewing doctors about their experiences, running time studies, carrying out cost calculations etc. (Spri, 1999b).

The third project to be highlighted is the North project. As Spri was taking the pulse of Swedish telemedicine several times during the 1990s, they wrote that not only the south region had comprehensive ongoing telemedicine projects, so did the north. However, Spri pointed to differences in application. Since the north region was sparsely populated but covered almost half of the country, opposite to the conditions in the south region, Spri reported that the north region had focused its applications on linking rural primary centres with specialist resources situated in more populated parts of the region (Holm-Sjögren et al., 1999). One of the projects Spri was referring to was the North project, funded by the Västerbotten County Council. It had started in 1995, under the heading "General telemedicine", with the explicit goal of bringing rural patient populations closer to specialist resources in a broad spectrum of conditions and injuries. Therefore it electronically connected GPs with specialists ranging from dermatologists to ear, nose, throat specialists, as well as orthopedists, at a university hospital (Hellström, 1998). In contradistinction to the above projects, the traces from the North project consist of participating doctors' accounts.

The paper trail from the 'the Eye' project likewise consists of doctors' descriptions of events, resulting in one of the most publicized telemedicine projects in Sweden. The Eye project, beginning in 1996, did not take place in either the south or north but in mid-Sweden, in the Stockholm region. The project was a joint effort of eye specialists and GPs to study whether it was possible to handle certain eye conditions already at the primary care level through a telemedicine application. By transmitting live video footage of certain eye conditions between GPs and the specialists at an eye hospital, the project team hoped to avoid the need for patients to receive a referral to a specialist, having to travel to yet another doctor. It received financial support from the Healthcare Administration of Stockholm County Council and the Knowledge Foundation (created by the parliament to amongst other things promote the use of IT) (Blomdahl et al., 2002).

\section{The Eye Project - Immediate Service}

In the Eye project, doctors experienced the distance to be overcome as that between the specialist hospital located in central Stockholm and the primary care centre twenty-five kilometres outside of the city (Blomdahl et al., 2003). With the aim of studying if telemedicine was suitable technically and practically within eye care, possible knowledge transfer to GPs, and patient attitudes, the Eye project went online in 1997 after diagnostic accuracy had been confirmed the year before. It did not target all possible eye conditions but focused the anterior part of the eye. The first reason for this was that it was understood amongst specialists that GPs often unnecessarily referred these conditions, and secondly, because the numbers of these cases were quite few, which would avoid putting too much stress on participating specialists (Blomdahl et al., 2002).

The primary care centre was equipped with a video eye microscope, a medical instrument normally only operated by specialists. The microscope was in turn connected to a video conference application, allowing for live transmission between the primary care centre and the hospital. To make it possible for GPs to easily reach a specialist when a suitable case showed up at the primary care centre, the participat- 
ing specialists were equipped with special pagers.

The arrangement of speedy access to specialists and live transmissions would prove critical for making the new configuration of the diagnostic process work. Not only did specialists sometime feel the need to direct GPs as to what part of the eye to capture with the microscope, something only possible during live transmission, GPs also noticed that patients with acute conditions were not keen on leaving the primary care centre to come back later. However, although much was done to allow for speedy access to specialists, the project still grappled with problems of reaching them in a timely manner, not least because when specialists were called upon they were sometimes in the middle of their own cases. The solution to minimize the problem as much as possible became to connect the telemedicine service to the emergency ward, which always had specialists on call (Blomdahl et al., 2003).

In their concluding remarks about the project, the doctors wrote that not only did telemedicine consultations provide good on-the-job training for GPs, it was much appreciated by patients too. They could now receive specialist care close to their homes, avoiding referrals to the hospital and having to spend time in yet another waiting room. However, enhancing the attractiveness of primary care was said not only to be beneficial to patients. Treating cases at the primary care level instead of having patients coming to the emergency ward would, in the end, result in a direct return for society at large, leading the project team to encourage a spread of similar telemedicine services to both other eye conditions as well as other specialities (Blomdahl et al., 2003).

But a paradox, as a participating general specialist called it (Löf, 2002), was that although GPs using the telemedicine system forwarded fewer and fewer anterior eye cases, they were in fact forwarding more total cases to the hospital than their colleagues. According to the project team, it turned out that a consequence of the increase in knowledge amongst GPs practicing telemedicine was that GPs become aware of all the cases they should have been forwarding to specialists (Löf, 2002; Blomdahl et al., 2003).

In attempting to make primary care the natural place for dealing with some conditions of the eye by making use of electronically mediated medical treatment the technical set up, the medical condition and the distance that doctors were trying to bridge became intertwined. In making patients comply and not travel the kilometres to the hospital, the system had to be arranged in such a way that speedy access to specialists was privileged. Hence the distance played a defining role in the choice of technical configuration. But contrary to the assumption that the application of telemedicine would result in fewer referrals to specialists, in fact it put even more pressure upon them. Due to the knowledge transfer between specialists and GPs, the latter became acutely aware of the number of patients that should have been seen by specialists.

\section{The Heart Project - Shortening Waiting Lists}

Just as the Eye project, the Heart project started with the intention of having more cases handled at the primary care level by using a telemedicine application. This time it was cardiac specialists at a hospital that were connected with two primary care centres in the county of Blekinge, targeting patients with cardiac insufficiency. But in the Heart project, it was not doctors who were to perform the project evaluation. Instead, Spri was put in charge of the 
assessment. Equipped with evaluation models based upon economics and requested by the board to have a county council and management perspective in mind, Spri and its health economists were to investigate the possible effects of having cardiac specialists available through video screens to every primary care centre in the county, a full scale implementation, as they called it (Spri, 1999b: 6).

However, even though the distance measured in kilometres between the primary care centres and the hospital was about the same as in the Eye project, it was not the travel distance to the hospital that was the centre of attention. Instead it was time to treatment that was too far away. Within existing practice, it took too long for patients to be diagnosed and have their treatment initiated. When telemedicine consultations began, in 1997, patients with cardiac insufficiency sometimes had to wait eight months before receiving treatment (Spri, 1999b: 31).

The telemedicine consultations operated by gathering GPs and specialists every two weeks through real time video transmissions in a virtual conference setting where they discussed record notes and ECG print outs, with the goal of speeding up the decision process. Thus, even though timely care was the focus in the Heart project, it did not aim to provide it instantaneously like in the Eye project. The targeted group of patients instead visited their GP and then returned home, awaiting further decision from the conference. If time to treatment was critical to heart patients, telemedicine applications were not to be used; these patients were to be rushed to the emergency ward (Spri, 1999b: 4). Hence, no GPs had to be able to rush a specialist to a workstation and no ECG machines had to be wired for live transmission to the hospital. To shorten time to treatment, a meeting every two weeks with print outs from patients' earlier visits at the primary care centre was considered sufficient, especially when waiting lists were measured in months (Spri, 1999b).

But in discussing the purpose of telemedicine consultation, Spri came to raise issues about the preferable way of organizing them. If the intention was to keep as many patients at the primary care level as possible, joint conferencing now and then of exemplary cases in order to educate GPs could be preferable. But if the aim was to start treatment as early as possible, then Spri argued that fast access to specialists should be in focus, perhaps by having a terminal at every GP's desk to be able to easily connect with the hospital (Spri, 1999b: 48). However, according to Spri, both options questioned established practices. If more cases should be kept at the primary care centre by educating GPs would this not make them something of specialists, themselves; how much should a GP really know? And if GPs could easily reach specialists trough a direct video link to discuss cardiac insufficiency cases, would this not be at the possible expense of other groups of patients? And, furthermore, Spri argued that when GPs' contacts with specialists were facilitated by telemedicine applications, patients that were before kept within the primary care system were now lifted up for discussion with specialists. The conferences had developed into an easy way for GPs to get a second opinion, making Spri ponder if this was due to a pent up need for specialist assistance or a case of overconsumption of specialist resources (Spri, 1999b: 45). Whatever the reason, Spri remarked that even though this should be beneficial to patients with cardiac insufficiency, since more of them were getting the opinion of a specialist, leading to possible improved public health in the long run, this was surely not the same thing as 
reduced costs for the healthcare system (Spri, 1999b: 47).

Again, it is visible in this case how an attempt to introduce telemedicine became configured in relation to the definition of the distance it was supposed to bridge. Since what was targeted in this project was not acute cases but time to treatment, measured in months, the project did not need to opt for immediate assistance by specialists. Therefore the system could function without either being linked to the emergency ward or the possibility to capture live transmission from medical instruments. And, according to Spri, a solution, having a computer at the GP's desk (similar to that in the Eye project) could in fact even be counterproductive for the healthcare system. Because their analysis of the Heart project indicated that the easier it was for GPs to reach specialists the more they would do so, leading to an increase in the consumption of care.

\section{The North Project - Connecting Rural Communities}

The North project had its system up and running in 1996. Its aim was to bridge the distance between specialists at the only university hospital in the north region with two primary care centres 240 and $370 \mathrm{~km}$ away. It, too, sought to forward specialist competence to GPs in an effort to improve service, this time for patients residing in the rural parts of the north (Carle et al., 2001). The project included cooperation by telemedicine applications between GPs and specialists within ear, nose and throat; dermatology (skin conditions); and orthopaedics by connecting the primary care centres and specialist clinics through a video conference system. In addition, the primary care centres were equipped with light tables to study x-rays, hand-held and document cameras to capture and show still photos of skin conditions, and the cavities of the ear, nose and throat. GPs were trained to operate specialist instruments (Carle et al., 2001).

Hence, the North project was not primarily targeting patients according to a specific body area as the Eye and Heart projects but was a 'general' telemedicine project, aimed instead towards patient groups living in remote areas (Made \& Hellström, 1999: 2). A participating professor wrote that, "[w]e often associate rural areas with a high quality of life, residing and living in a landscape of great natural beauty and in a relaxing environment". But then he continued by pointing out that in the context of care this landscape also forces patients to seek medical service far from home, taking time off work, while it likewise makes doctors feel isolated, unable to provide healthcare of the quality they would like (Hellström, 1997: 61). Together with his colleagues, he explained that patients living in these areas have "particular problems when they have to be referred to highly specialized medical expertise" (Made et al., 1999: 93). A medical journalist reporting on the topic of telemedicine in the north region noted that not only was it often many kilometres to care, but also that, due to the particular conditions of this region, with snowy and slippery roads, travel time could very well be doubled (Utbult, 1994: 44). It was in trying to even out these inequalities in the provision of care that the doctors in the North project argued for the usefulness of telemedicine. They believed that whether or not one lived in the mountains, inland, or in the city, one should receive the same medical service (Carle et al., 2001). Thus, the explicit goal of the North project team was not to keep rural patients at the primary care level in an effort to lessen the burden upon specialists, but instead to improve the availability of specialist care 
by introducing the possibility to contact them through wires (Carle et al., 2001).

In evaluating the increase of availability, the doctors reported that due to the possibility for GPs to reach the hospital through the telemedicine system, $30 \%$ more patients had their cases looked upon by specialists. Though fulfilling the goal of having more patients in contact with specialists, the doctors could not but wonder how the hospital clinics should cope with the possibility of having every rural primary care centre in the county connected to the university hospital. However, on one point they were clear: rural patients should have more of the share of specialists' resources (Made \& Hellström, 1999).

While the distance in both the Eye and the North project was measured in kilometres and both resulted in more cases being forwarded to specialists, they differed in other respects. While the aim of the Eye project was to improve the attractiveness of primary care amongst patients and to lessen the burden upon specialists, the North project was an attempt to increase the attractiveness of primary care by having more patients in contact with specialists. In the North project, place mattered for what telemedicine became. Here 'medicine at a distance' was being practiced to overcome the obstacles of a poor transportation infrastructure, a harsh climate and the shape of the landscape. If the Eye project aimed to stop patients from going the hospital, the North project instead worked to battle the problems patients had with getting to the hospital.

\section{The South Project - Bridging Organizational Shortfalls}

The South project started up in 1995 due to a government decision in the mid 1990's, authorizing the three counties in the southern most corner of Sweden to merge into the Scania region by the beginning of 1999 (Pettersson \& Holmer, 1998). In an effort to avoid having to close down county hospitals they were to be grouped into pairs, dissolving old county borders, leading to what a medical journalist reported had been called the formation of one "electronic gigantic hospital" (Björklund, 1996: 18). As such the project did not primarily target patients' travel distance since, as the professor in the North project wrote, in this densely populated region, highly specialized hospital care is often "just around the corner" (Hellström, 1997: 61). Instead the project aimed at closing any collaboration gap between hospital clinics in diagnostic imaging by putting telemedicine in place to make them work as a whole. Thereby the project team was hoping to improve both the quality and efficiency in the organization (Pettersson \& Holmer, 1998). By building a common electronic picture archive and communication system handling all types of radiology images, such as computer tomography and magnetic resonance scans, and integrating it with an information system, a more seamless radiology was to be accomplished. The linked hospitals would then divide tasks amongst themselves where the smallest hospital in each pair would carry out some elective care, the larger hospital handling more demanding tasks and emergency cases, and the two university hospitals in the region would deal with only highly specialized medicine (Pettersson \& Holmer, 1998). The chief county radiologist, and also head of the project, called it "one of the largest changes that have ever been accomplished in civil healthcare" (interview in the Swedish Medical Journal by Fällman, 1996: 3005). According to him the digitalization of diagnostic imaging in the new Scania region was not comparable to the small scale use of telemedicine applications which made it possible for a peripheral general radiologist 
to reach a specialist. Instead, he and a colleague described it as an important tool for the restructuring of the whole healthcare organization in the new region and of great national importance (Pettersson \& Holmer, 1998).

Likewise, the Collaboration Board of the South Healthcare Region and Spri understood the South project to be an integral part of the goal of improving both the quality and efficiency of the region's healthcare system through telemedicine applications. They argued that "[s] upported by telemedicine, organizational and structural changes should be carried out to increase cooperation between levels of care, and create better possibilities for care at the lowest possible care level" (Spri, 1997: 3). They hoped that telemedicine would improve communication between levels of care resulting in the "avoidance of unnecessary referrals from non-specialists" (Spri, 1997: 4), making it possible for specialists to refine their expert role by only handling relevant cases. Hence, as opposed to the North project, the goal was to increase cooperation between levels of care but this time to keep as many cases as possible away from highly specialized care. The professor in the North project summarized the difference between the North and South projects when he wrote that:

The distance between the [northern] towns of Umeå and Skellefteå is 130 kilometres. From the point of view of the healthcare sector it is of course a problem to distribute healthcare of the same quality and service level to all citizens in the county. It is, however, not only the rural area that is problematic. In densely populated areas, the question arises of how one should get the patient to the right care level and not unnecessarily burden the highly specialized care at the university hospitals. (Hellström, 1998: 5.)
In the South project then, and as part of a larger effort in the south region to streamline healthcare by telemedicine, care was in some cases considered to be too close to patients. In the south region, management was not aiming to bring more patients to specialists but just the right ones, keeping the rest at a distance from specialists. Instead of addressing place, telemedicine advocates in the South project addressed internal organizational gaps in cooperation between levels of care. By putting telemedicine applications in place, the distance between them could be closed, leading to a more streamlined healthcare.

\section{Dissolving Telemedicine}

Whereas applications of telemedicine became a sought-after solving a range of issues in different parts of the country, the state of variation in the practice of telemedicine also caused tension. The FCC, for instance, initiated the project Telemedicine - Regional and National Collaboration in attempting to coordinate activities. As a part of the project, a Carelink report stated that although hundreds of millions of Swedish crowns had been spent in more than one hundred telemedicine projects around the country, no general trend was discernable, making the report's author urge management at all levels to take action to achieve control (Leffler, 2001: 4-5). According to the IT in Health Services of Tomorrow report's working group, telemedicine was now part of the only way to tackle demands from patients of improved quality and services while containing monetary and staffing resources (Ds 2002:3: 79). But if this development was to take place in telemedicine, the report's authors argued that it demanded that the usability of telemedicine was addressed by the "right" persons, such as county council management and hospital execu- 
tives. Hence, telemedicine should no more be limited to doctors sitting in front of screens, since, as Spri (1998: 5) had stated, if telemedicine was an instrument to be used in direct medical practice, it was also a tool in the work to restructure the healthcare system. Such an understanding of telemedicine demanded national coordination. Addressing local problems with local technical solutions was, in this new context, not considered the way forward by national actors. As was made clear in the IT in Health Services of Tomorrow report, telemedicine could never be made to work just at a clinical level, in fact probably not even on a regional level (Ds 2002:3: 15). Instead, it was argued that telemedicine was part of the wider application of ICT within healthcare and, as such, should be integrated with other electronic systems used in administration and patient record keeping, assisting in crossing regional as well as organizational borders.

The shift towards telemedicine as an organizing principle for the healthcare system implied the suppression of rural matters as a justification for using telemedicine in efforts to increase the availability to care. In highlighting telemedicine's importance in transforming the healthcare sector at large by bridging the distance between different part of the healthcare system, Carelink and the IT in Health Services of Tomorrow report chose to downplay a focus on overcoming many kilometers by telemedicine. Carelink stated that even though the particularities of large rural areas in the country had been a reason for practicing telemedicine, the "focus on geographical distance is not that important today", emphasizing the technology's usefulness also where "geographical distances are short" (Carelink 2002: 22). Similarly, the authors of the IT in Health Services of Tomorrow report commented that the application of telemedicine was growing in the northern county councils due to the long travel distance to healthcare institutions, but considered this as a particular issue for rural areas of the country and not a part of the general importance of putting telemedicine in place (Ds 2002:3: 14-17).

However, the new framing of telemedicine, where Carelink and the authors of the IT in Health Services of Tomorrow report wished to coordinate different applications into alignment with a direction instead of staying "diffuse" as the FCC described it in this paper's opening quote, meant that the very existence of telemedicine was questioned. The FCC (2000a: 9; 2000b: 9) and Carelink (2002: 10) both repeated the phrase 4 : "many argue that it would be best to discard the concept of telemedicine and use the more general concept of IT instead." However, both agreed that this was "probably not practical. The "name issue' may appear to be unimportant, but problems arise if a concept does not accurately describe a technology." The authors of the IT in Health Services of Tomorrow report also commented upon the lack of a proper definition of telemedicine, asking if it was possible or even useful to separate telemedicine applications from other applications of ICT within healthcare (Ds 2002:3: 11-12). But, afraid of taking things too far, their solution became to keep 'telemedicine' but use it in pair with the term telecare, taken from similar efforts in the U.K. of modernizing the healthcare system. However, as has been pointed out by May et al. (2005), the introduction of telecare in the British healthcare system can be argued to involve abandoning the purpose of telemedicine as being about bringing patients closer to doctors, towards a reframing by policy actors of these technologies as tools of management control. In this changing context, and as was pointed out in discussion of the South project, these systems have become used 
in efforts to keep patients at a distance from scarce resources, for instance targeting the growing and burdening group of chronically ill. Similarly, the IT in Health Services of Tomorrow report, having stressed the importance of bringing management aboard in making ICT based healthcare delivery at a distance work according to their visions, also endorsed extending such devices to use in patients homes, both by caring staff as well as by patients and their relatives. Envisioning a future where the increasing numbers of elderly and chronically ill would be a heavy burden upon the healthcare system, the report pushed for developing solutions that could make patients themselves responsible for operating mobile ICT devices monitoring various bodily parameters (Ds 2002:3: 190).

These changes in how to proceed and in whom to target (management and patients instead of doctors) and what distances to close, would become the dominating trend in future coordinated efforts to solve issues around the availability of care by ICT in Sweden. So, ironically, while being the lengthiest document produced on telemedicine in Sweden by far, the IT in Health Services of Tomorrow report would simultaneously be a frontrunner of a new direction that would see telemedicine fading away from the general ICT based healthcare agenda. Instead, increasing attention has been paid to ICT devices operated outside of medical institutions as well as the development of an IT based healthcare system involving all levels of care, from healthcare activities in the home to national management. In 2006, the government issued Nationell IT-strategi för Vård och Omsorg (National IT Strategy for Healthcare and Social Services) to coordinate activities around the country. By 2010 it was renamed Nationell eHälsa (entitled National Strategy for eHealth in a slightly different English version), explaining the increasing interest in making use of ICT in preventive health rather than in medical interventions. Telemedicine was not mentioned.

\section{Concluding Discussion}

Throughout this paper, different accounts of telemedicine and what constitutes working technology have been contrasted. A comparison with two previously mentioned papers is a convenient way of summarizing the key findings of the account offered above. I will start by relating to Oudshoorn's study on how the introduction of technology to address issues of distance changes clinical practices (Oudshoorn, 2010). This will be followed by a discussion of the benefits of fluid and fixed relations through de Laet and Mol's paper about the working(s) of the Zimbabwe bush pump (de Laet \& Mol, 2000).

Oudshoorn shows that the introduction of ICT in order to mediate healthcare from a distance profoundly changes the practices involved, the outcome being a reconfiguration of what constitutes proximity in the healthcare delivery process. Similarly, the present study demonstrates that the introduction of telemedicine changed the delivery of care by reordering referral patterns through new spatiotemporal combinations, thus reconfiguring relations of proximity between levels of care. The focus of Oudshoorn's study, however, is on what she describes as an all too common misunderstanding in policy circles (Oudshoorn, 2010). This is the notion that technology is a neutral mediator which does not intervene in the practice of healthcare but merely facilitates a more efficient way of utilizing healthcare resources. The analysis offered above, by contrast, suggests that the protagonists of the different project constellations investigated all shared the goal of applying telemedicine precisely because 
they wanted to change the way care was delivered, taking care of patients at the lowest possible level of care. This corresponds with ambitions on the part of the government, the FCC and Spri, framing telemedicine as a tool allowing the dissolution of boundaries perceived as preventing a more efficient use of scarce specialist resources. Another picture, however, emerged in project evaluations. Instead of decreasing the burden upon specialists, the application of telemedicine consistently resulted in more patients being forwarded for a specialist opinion, either through referral or by electronic encounters. Hence these efforts to bridge the distance between GPs and specialists in order to accomplish a more rational use of healthcare resources appears to have been misguided. Contrary to the expectations of some policy makers, keeping things apart seems to have contributed to containing resources $^{5}$.

Whether this kind of distance is considered a problem or an asset, Oudshoorn's argument can be taken one step further. Not only did the introduction of ICT change healthcare practices, telemedicine itself took on different shapes, turned into different things, as it was arranged to fold space and time in diverse ways. In this respect, the present paper demonstrates the usefulness of a focus on spatiotemporal matters in sociotechnical studies of what constitutes working technology. The preferred arrangement of humans and non-humans and what constituted working telemedicine, varied in accordance with distinct ways of formatting distance. What distance was and what telemedicine was expected to do became intertwined in various configurations as different project constellations attempted to address the availability of care. Distance, as defined by the actors involved, played a key role in determining what telemedicine became.
As in de Laet and Mol's story of the Zimbabwe bush pump (de Laet \& Mol, 2000), telemedicine's relations were in motion, predominantly being fluid rather than fixed, changing across contexts and situations. What telemedicine was constantly fluctuated with its position in the heterogeneous web of relations. Just as the pump shifted in appearance, from one village to the next, concerning what tasks to perform, what role to play, telemedicine changed in relation to its environment. Telemedicine became framed by place. Its set ups of hardware, software and medical instruments always seemed to be shifting, as it was caught up in regional and national politics, being reconfigured according to medical practices and conditions. Yet all these different positions were represented as Swedish telemedicine. Thus, just as the bush pump, on de Laet and Mol's interpretation, gained currency because of its ability to vary and adapt, telemedicine appealed to local and regional actor pushing projects all over the country, due to its capability of addressing a range of healthcare-related spatiotemporal situations.

However, at the Stockholm offices of Spri, Carelink, and the FCC, the fluid topology of telemedicine caused tensions. Not only did the application of the technology dissolve the distance between GPs and specialists, telemedicine itself was dissolving in these policy circles. For all its utility as a vehicle promoting cooperation and the distribution of knowledge from centres of expertise to non-specialists, policy actors regarded telemedicine as an instrument suiting their efforts at achieving a more streamlined healthcare organization. Fluid relations, defined by de-centering, cooperation and distribution, encountered networks of fixed relations defined as control, order and hegemonic aspirations. Having no interest in controlling things, in ordering times and spaces, according to 
de Laet and Mol (2000), the inventor of the Zimbabwe bush pump was happy to see the device drift. Carelink and the authors of the IT in Health Services of Tomorrow took a very different approach. Trying to set their preferred version of telemedicine in place, they gave some distances priority over others. In line with the argument by Murdoch (1998), these policy actors set out to exercise power by arranging various distances in a hierarchical order of precedence. Because to them telemedicine had to be more than yet another tool in the arsenal of medical instruments or simply something to be deployed when facing external obstacles of the landscape. In their version, telemedicine was instead a means of aligning clinical work to the need for a more resource-efficient healthcare system. In this version, bringing more patients in closer proximity to doctors was not necessarily the right path to choose. However, neither Carelink nor the FCC managed to take control over telemedicine and stabilize their preferred organizational version. While medical professionals succeeded in getting telemedicine to work as part of their efforts at addressing situated issues of space and time, the requirements made in the IT in Health Services of Tomorrow report, stating that telemedicine could probably only work on a national level and never solely at the clinical level, were never fulfilled. Not being able to set their version of telemedicine in place, the policy actors involved began to lose interest. Instead they increasingly turned their attention to the emerging field of electronically mediated home healthcare, envisioned as a means to shift some parts of healthcare out of the traditional care institutions altogether. Telemedicine was increasingly backgrounded. Relegated from its role as a vital part of a strategy of reforming the Swedish healthcare system by ICT, it began to fade away from policy papers.
Hence the effects of fluidity are very different in the Zimbabwe bush pump story and the case of Swedish telemedicine. Whereas the bush pump, apparently, thrived as a result of its ability to change relations, the fluidity of telemedicine eventually caused problems in policy circles. While the fluidity of telemedicine contributed to its diffusion throughout clinics around the country, appealing to medical professionals and policy actors alike, its failure to take on the character and direction preferred in policy circles resulted in its losing significance as a means of accomplishing a more efficient healthcare system. In this paper, the utility of technological flexibility has been emphasized, but so have complications arising from actors' difficulties to align a technology into a common frame of reference. On the one hand, technologies representing a frozen set of relations may turn out to be brittle, fracturing all too easily. On the other hand, an unduly fluid character may cause them to evaporate, to dissolve. For technology to travel well, it seems, both fixed and fluid relations are essential.

\section{Acknowledgements}

I would like to thank Ingemar Bohlin and Ericka Johnson for constructive comments and suggestions as well as invaluable assistance on language matters. I also want to express my gratitude to The Swedish Foundation for International Cooperation in Research and Higher Education for giving me the opportunity to spend 5 months at the UC Davis STS-wing under the tutelage of Joseph Dumit who offered thoughtful advice on very early drafts of the paper. Thanks also to the two anonymous reviewers and the editor for seeing the potential in the paper and offering recommendations for improvements. 


\section{Notes}

${ }^{0}$ This article was edited and approved for publication by Brit Ross Winthereik.

${ }^{1}$ This paper is based on an analysis of documents about telemedicine and related topics published by Swedish authors. Hence, not everyone's voice is heard (such as that of patients); published voices are considered. The documents have been found by trawling various data bases. By following the trail of references and performing searches at the web sites of administration bodies and ministries, the empirical material has been further extended. The time period for this paper has been limited to between 1994, the year after telemedicine was promoted to the level of a MeSH term in Pubmed, and 2003, the year the last article describing one of the four projects was published, ending with a short glimpse into later events. Some of the accounts of events are told by medical journalists.

${ }^{2}$ Author's translation, as are all Swedish to English translations in this paper.

${ }^{3}$ In the empirical material, actors alternate between using IT and ICT in relation to telemedicine. Since no actor has made any effort to point to the difference that sometimes can be found between these two, I will henceforth use ICT whenever possible.

${ }^{4}$ The two phrases reads in Swedish: "från många håll höjs röster om att det vore bäst att utmönstra begreppet telemedicin och istället använda endast samlingsbegreppet IT", and "tycks detta inte vara praktiskt möjligt. 'Namnfrågan' kan tyckas oväsentlig, men det kan ge problem om ett begrepp inte korrekt beskriver en teknologi."

${ }^{5}$ I thank one of the reviewers for kindly suggesting that I spelled this point out more clearly.

\section{References}

Bejerot, E. \& H. Hasselbladh (2008) 'Det nya Regleringslandskapet' in Bejerot, E., Hasselbadh, H., \& Gustavsson, R. (eds) Bortom New Public Management (Lund: Academia Adacta AB): 107-22.

Bijker, W.E. (1995) Of Bicycles, Bakelites, and Bulbs: Toward a Theory of Sociotechnical Change (Cambridge, MA: MIT Press).

Björklund, I. (1996) 'Det Elektroniska Jättesjukhuset,' Landstingsvärlden 83(4): 18-19.

Blomdahl, S., B. Calissendorff \& R. Löf (2003) 'Distansundersökning av Ögat i Nytt Samarbete Specialist-Vårdcentral', Läkartidningen 100(51-52): 4284-85.

Blomdahl, S., B. Callissendorff \& U. Jackobsson (2002) 'Patient-Focused Urban Tele-Ophthalmology Services', Journal of Telemedicine and Telecare 8(Supplement 2): 43-44.

Callon, M. (1991) 'Techno-Economic Networks and Irreversibility' in Law, J. (eds), A Sociology of Monsters: Essays on Power, Technology and Domination (London: Routledge): 132-61.

Carelink (2002) Telemedicin - En Resurs i Vård och Omsorg (Stockholm: Carelink).

Carle, L. ,C. Made \& S. Hellström(2001) 'Telemedicin i Glesbygd ger Nöjda Patienter och Högre Kompetens', Läkartidningen 98(38): 4049-52.

Cartwright, L. (2000) 'Reach Out and Heal Someone: Telemedicine and the Globalization of Health Care'. Health 4(3): 347-77.

de Laet, M. \& A. Mol (2000) 'The Zimbabwe Bush Pump: Mechanics of a Fluid Technology', Social Studies of Science 30(2): 225-63.

Ds 2002: 3 (2002) Vård ITiden - Strategier och Åtgärder för att Bredda Användningen av Telemedicin och Distansöverbryggande Vård (Stockholm: Fritzes). 
Fällman, H. (1996) 'Bildflöde under Åkrarna på Österlen Början till Samordning av Tio Sjukhus', Läkartidningen 93(36): 3004-06. Graham, S. (1998) 'The End of Geography or the Explosion of Space? Conceptualizing Space, Place and Information Technology', Progress in Human Geography 22(2): 165-85.

Haraway, D. J. (1997) 'Modest_Witness@ Second_Millenium, in D. J. Haraway (eds) The Haraway Reader (London, Routledge): 223-50.

Hellström, S. (1997) 'Telemedicin i ett Glesbygdsperspektiv' in Svensk Medicin 54 (Stockholm: Spris förlag): 61-64.

Hellström, S. (1998) 'Telemedicin. Erfarenheter från ÖNH-konsultationer i Västerbotten och Skövde', Svensk ÖNHtidskrift 4: 5-6.

Hinchliffe, S. (1996) 'Technology, Power, and Space - the Means and Ends of Geographies of Technology', Environment and Planning D: Society and Space 6: 659-82.

Holm-Sjögren, L., C. Sandberg \&H. Törnqvist (1999) 'Telemedicine in Sweden - a Diffusion Study', Journal of Telemedicine and Telecare 5(Supplement 1): 63-64.

Landstingsförbundet (1997) Ökad ITanvändning och IT-samverkan i Hälso- och Sjukvården (Stockholm: Landstingsförbundet).

Landstingsförbundet (2000a) What Is the Potential for Telemedicine? (Landstingsförbundet).

Landstingsförbundet (2000b) What Are the Barriers Facing Telemedicine? (Landstingsförbundet).

Landstingsförbundet (2000c) Vilken potential finns för telemedicin? (Landstingsförbundet).

Latour, B. (1987) Science in Action: How to Follow Scientists and Engineers Through Society (Cambridge: MA Harvard University Press).
Law, J. (1987) 'Technology and Heterogeneous Engineering. The Case of the Portuguese Expansion' in W. E. Bijker, T.P Hughes and T. J. Pinch (eds) The Social Construction of Technological Systems: New Directions in the Sociology and History of Technology (Cambridge, MA: MIT Press): 111-34.

Law, J. (2002) 'Objects and Spaces', Theory, Culture \& Society 19(5/6): 91-105.

Law, J. \& A. Mol (1995) 'What is Social Context? A Note on Boundaries, Fractals and Technologies', paper presented at Keele University Centre for Social Theory and Technology Seminar.

Law, J. \& A. Mol (2001) 'Situating Technoscience: An Inquiry into Spatialities', Environment and Planning D 19: 609-21.

Leffler, J. (2001) Telemedicine from a Management Perspective: From Trials to Standard Practice! (Stockholm: Carelink).

Löf, R. (2002) 'Erfarenheter av Telemedicinska Konsultationer,' Distriktläkaren 7: 11-13.

Made, C., L. Carle, O. Söderberg \& S. Hellström (1999) 'Tele-Otolaryngology Consultations Between two Rural Primary-care Centres in Southern Lapland and the University Hospital of Umeå,, Journal of Telemedicine and Telecare 5(Supplement1): 93-94.

Made, C. \& S. Hellström (1999) 'Telemedicinkonsultationer mellan Primärvårdsenheter i Tärnaby/Storuman och Specialistkliniker vid NUS, Evaluation Report.

May, C., M. Mort, F. Mair \& T. Williams (2001) 'Factors Affecting the Adoption of Telehealtcare in the United Kingdom: The Policy Context and the Problem of Evidence', Health Informatics Journal 7(3-4): 131-34. 
May, C., M. Mort, T. Williams, F. Mair \& L. Gask (2003) 'Health Technology Assessment in its Local Context: Studies of Telehealthcare', Social Science \& Medicine 57(4): 697-710.

May, C., T. Finch, F. Mair \& M. Mort (2005) 'Towards a Wireless Patient: Chronic Illness, Scarce Care and Technological Innovation in the United Kingdom, Social Science \& Medicine 61: 1485-94.

McLean, C \& J. Hassard (2004) 'Symmetrical Absence/Symmetrical Absurdity: Critical Notes on the Production of Actor-Network Accounts, Journal of Management Studies 41(3): 493-519.

Ministry of Health and Social Affairs (2002) 'IT in the Health Services of Tomorrow', available at http://www.regeringen.se/ content/1/c6/01/18/92/c38d5418.pdf [referenced June 1, 2010].

Mort, M., C.R. May \& T. Williams (2003) 'Remote Doctors and Absent Patients: Acting at a Distance in Telemedicine?', Science, Technology, \& Human Values 28(2): 274-95.

Mort, M., T. Finch \& C. May (2004) 'Telemedicine and Clinical Governance: Controlling Technology - Containing Knowledge, in S. Harrison and A. Grey (eds) Governing Medicine: Theory, Practice and Prospects (London: Open University Press): 107-21.

Murdoch, J. (1998) 'The Spaces of ActorNetwork Theory', Geoforum 29(4): 35774.

Nationell eHälsa (2010) (Stockholm: Socialdepartementet).

Nationell IT-Strategi för Vård och Omsorg (2006) (Stockholm: Socialdepartementet).

National Strategy for eHealth (2010) (Stockholm: Socialdepartementet).
Oudshoorn, N. (2010) 'Physical and Digital Proximity: Emerging ways of health care in face-to-face and telemonitoring of heart-failure patients' Sociology of Health \& Illness 31(3): 390-405.

Pettersson, H. \& N. G. Holmer (1998) 'Teleradiology in Southern Sweden - A Tool for Reorganization of Health care and for Organization', Computer Methods and Programs in Biomedicine 57: 13-19.

Proposition (Government bill) 1995/96:125 (1996)'Åtgärderförattbredda ochutveckla användningen av informationsteknik'.

Quattrone, P. \& T. Hopper (2005) 'A 'TimeSpace Odyssey': Management Control Systems in Two Multinational Organisations', Accounting, Organizations and Society 30(7/8): 735-764.

Rogers, E. M. (1995) Diffusion of innovation, 4th ed. (New York: Free Press).

Spri (1997) Telemedicin i Södra Sjukvårdsregionen: Förstudie (Lund: Samverkansnämnden, Södra sjukvårdsregionen; Stockholm: Spri).

Spri (1998) Videokonferenser - Lönar det Sig? (Stockholm: Spri).

Spri (1999a) Det gör Spri!: Exempel ur Verksamheten (Stockholm: Spri).

Spri (1999b) Utvärdering av Telemedicinska Konsultationer inom Kardiologi (Stockholm: Spri).

Star, S. L. (1991) 'Power, Technology, and the Phenomenology of Conventions: On Being Allergic to Onions', in J. Law (ed) A Sociology of Monsters? Essays on Power, Technology and Domination, Sociology Review Monograph 38 (London: Routledge): 26-56.

Thrift, N. (1996) Spatial Formations (London: Sage). 
Utbult, M. (1994c) Vård och Råd på Tråd: Reportage av Mats Utbult om Distansdiagnostik och Telemedicin som Stöd för Samverkan och Lärande i Sjukvården - från Nordkalotten till SkåneBlekinge, Teldokrapport 85. (Farsta: Teldok).
Jesper Petersson

Department of Sociology

University of Gothenburg

Box 720

40530 Göteborg

Sweden

jesper.petersson@sts.gu.se;

jesper_petersson@hotmail.com 